Dept. of Surgery

Fac. Vet. Med., Assiut University.

\title{
SURGICAL MANAGEMENT OF COMPLICATED INJURIES OF THE TAIL IN SHEEP AT AL-GASSEEM
} (With 7 Figures)

\author{
By \\ H.A. YOUSSEF* \\ Dept. of Vet. Med., College of Agri. \& Vet. Med., King Saud, Univ., \\ Al-Gasseem Branch, K.S.A. \\ (Received at 15/6/1999) \\ العلاج الجراحى للاصابات الوخيمة فى الية الأغنام بالقصيم \\ هارون علي بيوسف
}

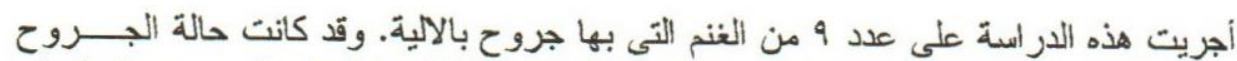

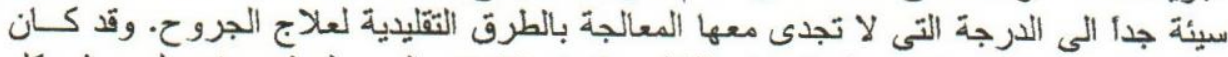

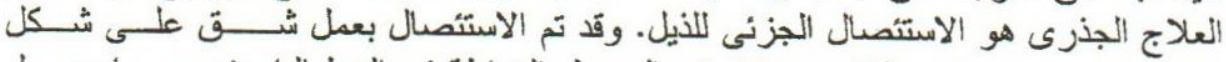

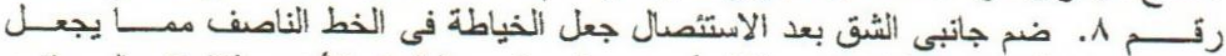

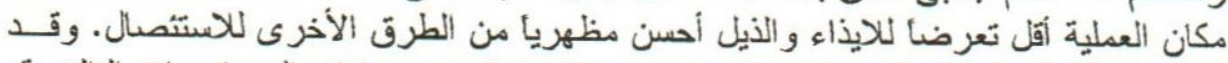

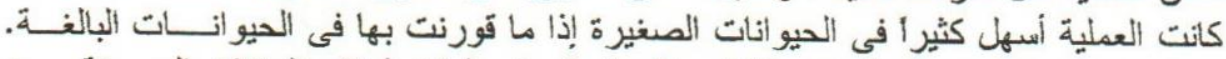

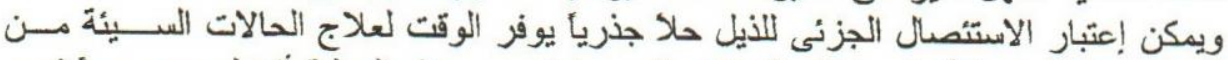

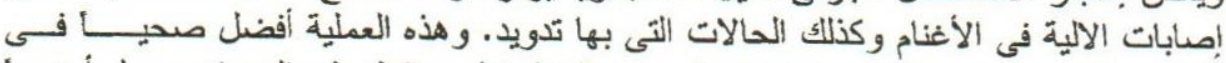

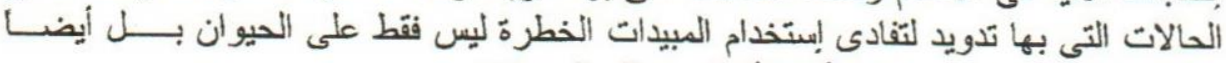

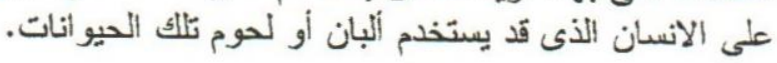

\section{SUMMARY}

The present study was carried out on 9 sheep with injuries in the tail. The wounds were severely complicated to the degree that the routine wound management seemed to be of no value for treatment. The radical treatment for these complicated cases was partial amputation of the tail. Amputation by making an incision in the shape of inverted V letter seemed to be an easy and efficient approach for treatment. Coapitation of the sides of the amputation stump made the sutures to be in the midplane where the operative site became less prone to irritation 
postoperatively and gave the tail good appearance. The operation was easier in lambs than in the adult sheep. Partial amputation can be considered a radical intervention that saves time in treatment of the severely complicated injuries and the cases which have myiasis. The approach avoids the use of insecticides which are dangerous not only for the animal life but also for the people who may consume the milk or meat of the treated animals.

\section{Key Words: Tail Al-Gasseem}

\section{INTRODUCTION}

The surgical affections of the tail in some domestic animals were described by Aziz (1990). In sheep, Kassem (1989) mentioned some surgical affections for the tail. Youssef and Alam El-Din (1991) discussed the indications and techniques for tail amputation in the adult sheep. They stated that complete amputation of the tail in adult sheep is much more easier than partial amputation.

It is the aim in this study to improve the surgical interventions while dealing with the complicated tail injuries in sheep especially the cases which have myiasis.

\section{MATERIALS and METHODS}

The present study was carried out on 9 sheep (4 lambs and 5 adult sheep). All cases were admitted with old complicated wounds at different levels within the distal two thirds of the tail. Myiasis was apparent in most cases.

The animals were tranquillized by the intramuscular injection of Calmvet $^{*}$ in a dose rate of $2 \mathrm{mg} / 10 \mathrm{~kg}$ of the body weight, 10 minutes preoperatively. The operations were performed under effect of lumbosacral epidural analgesia using lidocaine hydrochloride ( $2 \%$ solution).

*: Vetoquinol S.a., Manyvernois, 70200 Lure, France. 
Preoperatively, a tourniquet was applied around the tail base and the wounds were cleaned. The wound surface was drapped. The operative site was prepared aseptically. Surgery was performed by incising the dorsal and ventral surface in the shape of inverted V letter; where the incision apex is proximal. The incisions were done proximal to the injured part by an area sufficient to get rid of all the contaminated and affected tissues. The dorsal and ventral incisions were deepened to reach the vertebrae and the vesseles were ligated. Disarticulation was done at the level of the apex of the incision. The subcutaneous tissue along with the fat were coapitated using interrupted 8-Figure sutures (Coated Vicryl*). The skin was closed with interrupted mattress sutures. The skin sutures were removed 10 days postoperatively.

\section{RESULTS}

Most cases had Myiasis ( 8 cases) and the injuries were complicated severely to the degree that the routine wound management appeared to be of no value (Fig. $1 \& 2$ ). The radical treatment for the complicated injuries of the tail in sheep was the surgical amputation. Partial amputation of the tail was easier in the young animals (Fig. 3) than in the adult ones (Fig. 4, 5, 6\& 7). The distal amputations were easier than the proximal ones. The subcutaneous sutures were more efficient in the young than in the adult animals. Application of a tourniquet around the tail base has an aid in minimizing the intraoperative hemorrhage. Isolation of the distal part of the tail facilitated its manipulation intraoperatively. In the adult animals where the subcutaneous sutures where less effective, the use of the vertical mattress sutures of the skin gave an aid for coapitation of the deeper tissues. It was not practical to use the blunt dissection where it was difficult to search for the blood vessels inside the massive fat. The sharp cutting gave an aid to get red of the amputated part faster. Then the bleeding vessels in the amputation stump could be caught and ligated. When the tail was massive, some fat from the amputation stump was excised to facilitate efficient coapitation.

**: Ethicon, Inc. 


\section{DISCUSSION}

Tail injuries in sheep may be severely complicated to the degree that they can not be treated in the routine manner of wound management. Ramadan (1994) indicated the use of topical and/or systemic insecticides with wound dressing for treatment of some cases in complicated wounds with mayiasis in camels.

Partial amputation of the tail in sheep may be considered a radical treatment for the severely complicated cases of tail injuries. Amputation is not only a radical time saving intervention but also is an approach that avoids the use of the insecticides for the cases complicated with myiasis. The use of the insecticides is not only dangerous for the animal life but also the life of the people who might use the milk or the meat of the treated animals.

The present technique for partial tail amputation in sheep seemed to be an easy and efficient approach for treatment of the complicated tail injuries. The sutures in the present technique are less prone to irritation where they are in the midplane and not in the periphery. The shape is also more sightly in appearance in comparison to the other techniques described by Youssef and Alam-El-Din (1991).

\section{REFERENCES}

Aziz, M.S. (1990): Comparative and applied surgical anatomy of the tail with special reference to its surgical affections in some domestic animals. M.V.Sc. Thesis, Fac. Vet. Med., Assiut Univ., Assiut, Egypt.

Kassen, M.M. (1989): Some surgical affections of the tail in sheep. Proc. Third Scientific Congress, Fac. Vet. Med., Assiut Univ., Assiut, Egypt, P. 25-31.

Ramadan, O.R. (1994): Surgery and Radiology of the dromedary camel. First ed., Al-Jawad printing pres, Kingdom of Saudia Arabia, P. 74-77.

Youssef, H.A. and M.A. Alam El-Din (1991): Studiees on tail amputation in adult sheep. Assiut Vet. Med. J., 25 (50): 151-159. 


\section{LEGENDS}

Fig. (1): A complicated wound (myiasis) in the tail of a lamb. A tourniquet is applied around the tail base.

Fig. (2): A complicated wound (myiasis) in the tail of an adult sheep.

Fig. (3): Tail amputation in a lamp.

Fig. (4): The amputation stump before coapitation of the sides of the incision.

Fig. (5): Partial amputation of the tail in an adult sheep after excision of the injured part and coapitation of the sides of the amputation stump.

Fig. (6): Tail amputation in an adult sheep.

Fig. (7): An adult sheep after partial amputation. More than twothirds of the tail was excised. 
Assiut Vet. Med.J. Vol. 41 No. 82, July 1999.
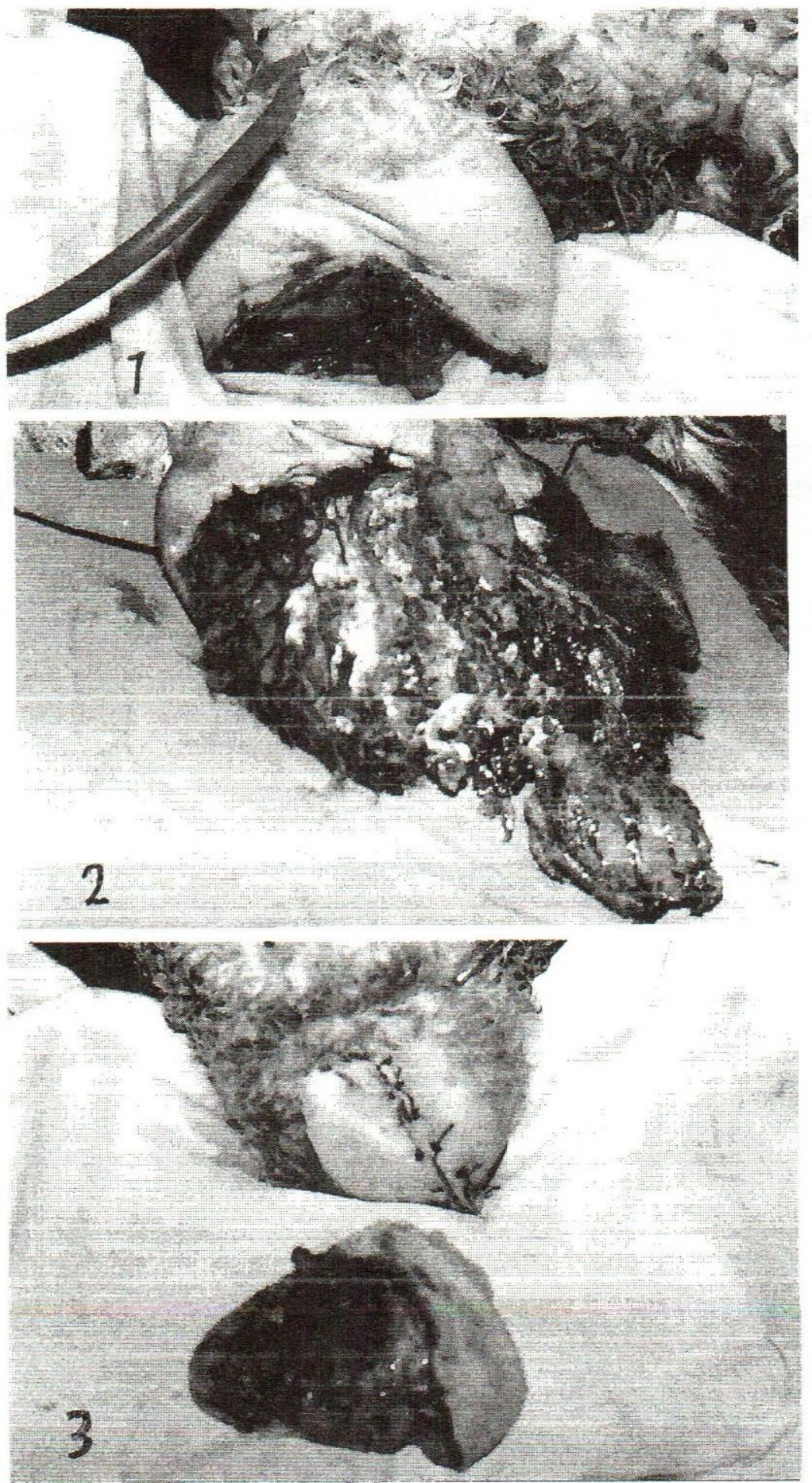
Assiut Vel. Med.J. Vol. 41 No. 82, July 1999.
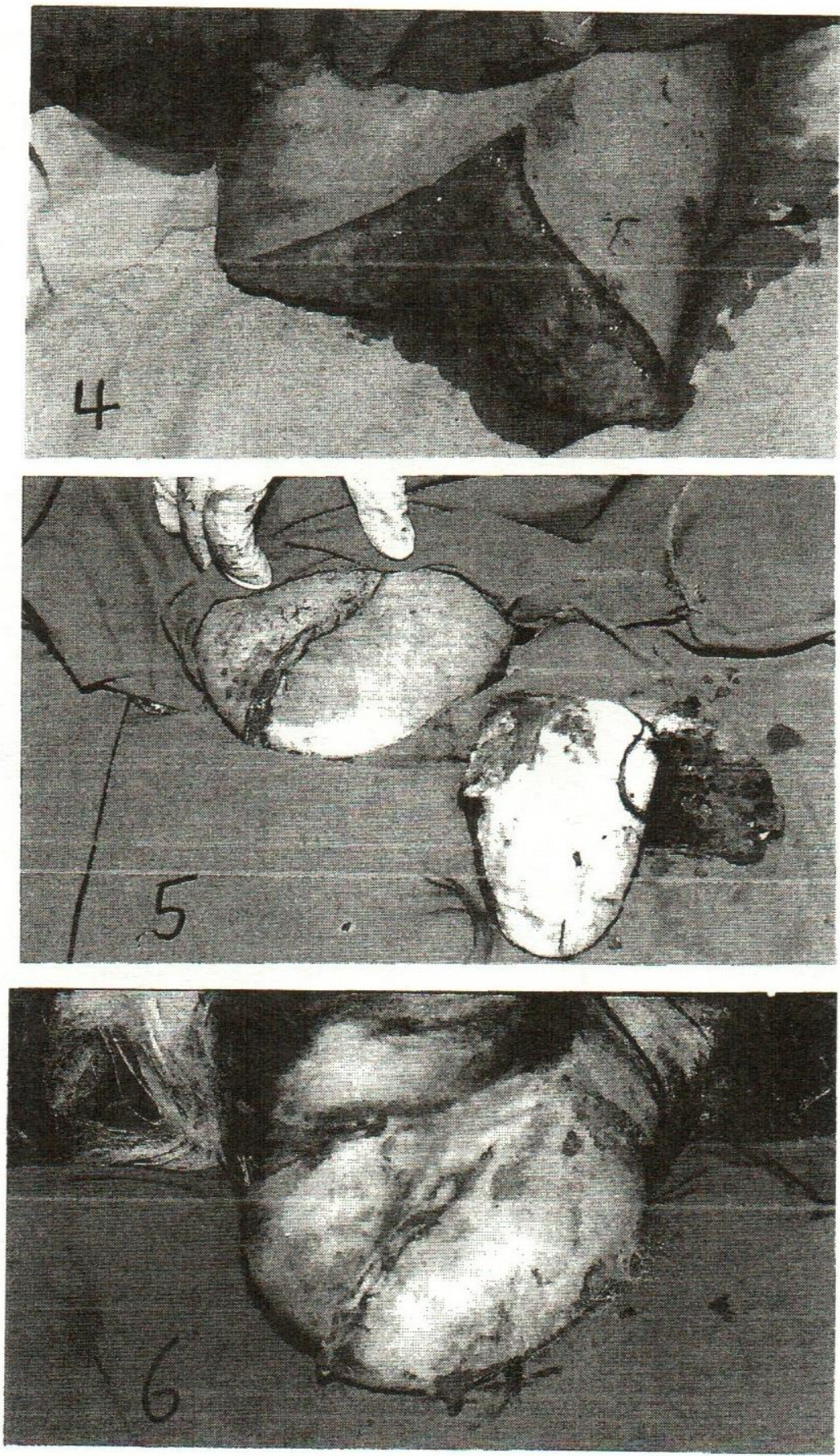


$$
\text { Assiut Vet. Med. J. Yol } 41 \text { No 82, July } 1999 .
$$

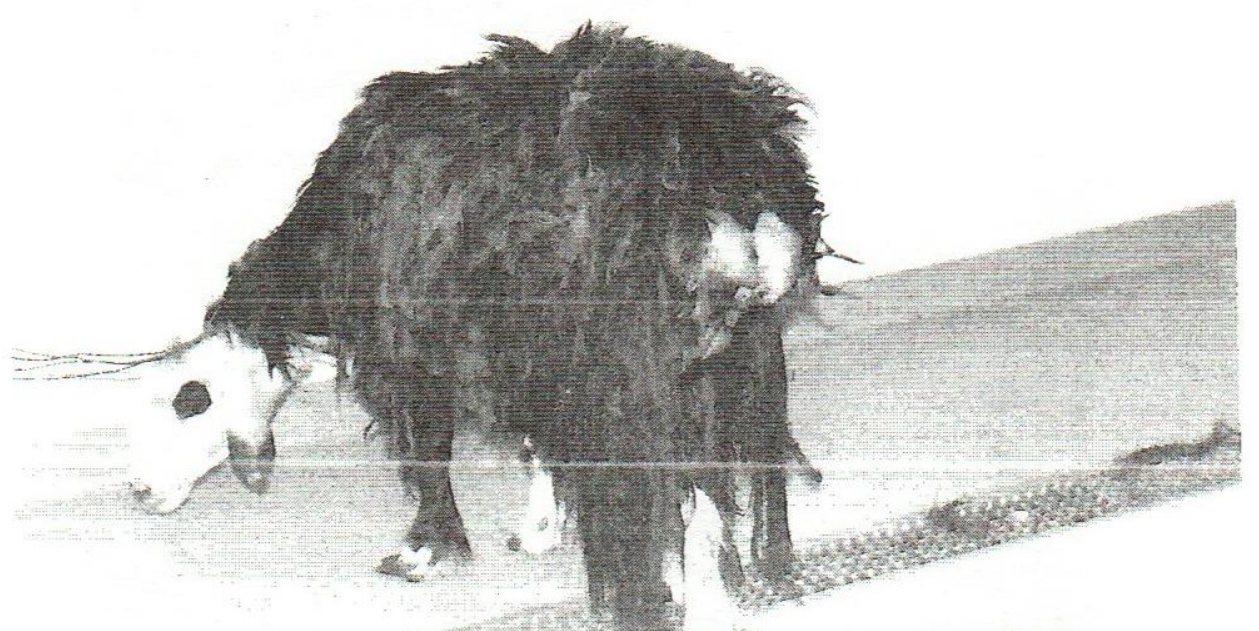

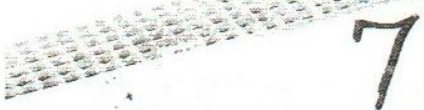

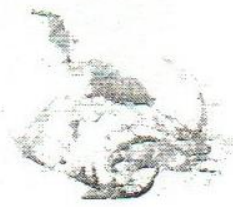

